\title{
SPOTLIGHT
}

\section{The health impacts of climate change}

\author{
Can we at last accept that the climate is changing, that we are making it happen, and that there are \\ profound implications for us? Chris Rapley answers the key questions
}

\author{
Chris Rapley professor of climate science \\ Department of Earth Sciences, University College London, Gower Street, London WC1E 6BT
}

No science is ever completely settled. However, among the tens of thousands of scientists working in the field of climate science worldwide there is almost complete agreement that our climate system is changing, and that human activities are the predominant driving force. This agreement is remarkable given what a belligerent, argumentative lot scientists are, and that they take great pleasure in proving each other wrong. I want to address the following five questions: Has the climate changed before? Are the current circumstances unusual? Is the planet warming (and how do we know)? Is it us (and how do we know)? And does it matter?

\section{Has the climate changed before?}

Yes, on many timescales and for many reasons, not least because the energy output of the Sun varies. As the primary energy source of the Earth system, the Sun drives the motions of the ocean and the atmosphere, as well as energising the photosynthesis on which the food chain of life depends. The Sun's luminosity has increased by about $30 \%$ over the 4.5 billion year lifetime of the planet, and its energy output fluctuates, albeit at the $0.1 \%$ level. So yes, the Sun changes, and in doing so it drives changes in the Earth's climate system.

In addition, the growth of the biosphere itself has completely altered the chemistry of the atmosphere. Before the rise of the cyanobacteria, some 2.5 billion years ago, there was no oxygen in the atmosphere. As Jim Lovelock pointed out in his Gaia theory, ${ }^{1}$ the Earth's biology isn't a passenger. It is an active, interconnected part of the system that drives change that affects the climate system. This is especially true of heat trapping trace gases, such as carbon dioxide, which keep the surface of the planet significantly warmer than would otherwise be the case. Changes in the carbon cycle, and hence in the carbon dioxide content of the atmosphere, have had major impacts on global temperatures, and have been implicated in continental scale transformations, such as the glaciation of the Antarctic (see fig 1). $\Downarrow$

Even the slow drifting of the continents changes the way that heat is absorbed and reflected from the surface of the planet, which alters the climate system. We know that within recent geological history subtle changes in the tilt, procession, and shape of the Earth's orbit have caused either 41000 year or 100 000 year cycles of ice ages and interglacial periods.

So there is plenty of evidence that the system is driven by change. In addition, because it is a highly interconnected and complex system, it exhibits internal variability on a variety of timescales.

Those who would deny that climate change is a problem often point to these forms of variability, as if it made everything all right. But what this variability tells us is that the climate system is quite a frisky beast. It reacts to relatively subtle driving forces and can respond dramatically.

\section{Are the current circumstances unusual?}

In 2011 the world's population exceeded seven billion people. We know that human impacts on the planet scale with population and consumption, and that these impacts can be mediated or reduced by the efficiency with which we use resources and energy. Paul Crutzen, winner of the Nobel prize for chemistry, has dubbed the present epoch the Anthropocene, because future generations will see the evidence of humans as the dominant influence on the planet at this stage in its geological history. ${ }^{2}$ We are in a "no analogue state": there has never been anything like it before. We have, for example, transformed nearly 50\% of the Earth's land surface, and the effects on habitats, species, and the nitrogen cycle through our use of fertilisers have been dramatic.

Our biggest impact, from the point of view of climate change, has been the burning of half a trillion tonnes of fossil fuel carbon to power the wealth and prosperity of the modern world. By doing so, we have unwittingly increased the concentration of carbon dioxide in the atmosphere by 100 parts per million. This is the same amount as the natural shift between a glacial period and an interglacial period, when global temperatures change by about $5^{\circ} \mathrm{C}$. But this has occurred in 100 years, which is over 
100 times faster than anything found in the geological ice core record (see, for example, Luthi et $\mathrm{al}^{3}$ ).

In the mid-19th century, John Tyndall was amazed to discover that the nitrogen and oxygen constituting the bulk of the atmosphere are transparent to heat. It is the trace gases - carbon dioxide, water vapour, and others - that are the active ingredients that prevent heat radiating straight out to space. Without trace gases the surface of the Earth would be $30^{\circ} \mathrm{C}$ cooler than it currently is - or minus $15^{\circ} \mathrm{C}$ on average - and the surface of the planet would be frozen.

The physics of this greenhouse effect has been well understood for more than 100 years. Indeed, at the end of the 19th century Svante Arrhenius, the Swedish atmospheric chemist, spent two years calculating by hand the effects of doubling the amount of carbon dioxide in the atmosphere, His figure of a rise of about $4^{\circ} \mathrm{C}$ is not very far from what modern models and calculations have produced. Interestingly, Arrhenius thought warming would be a good thing, because it would increase agricultural productivity. But he also thought it would take mankind 1000 years to achieve it. He had no concept of how quickly we would dig up and burn the Earth's coal, oil, and gas.

\section{Is the planet warming?}

To answer this question it is especially important to look at two places: the ocean and the ice caps. The ocean covers $70 \%$ of the planet's surface and is darker than the land. As a result, it absorbs about $90 \%$ of the heat imbalance due to the enhanced greenhouse effect.

So what do we observe? Until about 20 years ago the source of sea level measurements was a large number of tide gauges distributed around the world's coasts. It's difficult to correct their readings for pressure and ocean dynamic effects, and to calculate a single measure of sea level averaged over the surface of the entire ocean. Nevertheless, we have a record that extends back to the early 20th century. Although tide gauge data are still an important source of information, these days data from satellites continuously orbiting the planet are used. Radar instruments on satellites fire radio pulses down to the ocean's surface, and every 10 days or so provide a figure for the average height of the ocean, relative to the Earth's centre of gravity.

From the combination of the two datasets we know that over the 20th century the sea level was rising at about 1.8 to $2 \mathrm{~mm}$ a year. Before that, for at least 2000 years and maybe longer, it had been stable, having settled after the massive $120 \mathrm{~m}$ rise at the end of the last ice age in the transition to present climatic conditions. So although $1.8 \mathrm{~mm}$ per year doesn't sound very much, it issignificant. But what we find now is that sea level is rising at about $3.5 \mathrm{~mm}$ a year, which corresponds to an increase of at least $35 \mathrm{~cm}$ by the end of this century, assuming no futher acceleration. In fact, the projections of the Intergovernmental Panel on Climate Change (IPCC) in its fourth assessment report lie in the range of 18 to $59 \mathrm{~cm}$, though they take no account of the contribution from the ice sheets. ${ }^{4}$ More recent and comprehensive estimates suggest that even $2 \mathrm{~m}$ might be possible. ${ }^{5}$ Sea level rise will increase the likelihood of extreme high water events overwhelming sea defences, critical for low lying coastal areas. A rise of $50 \mathrm{~cm}$ in the average level, for example, can change the probability of an extreme high water from a 1 in 1000 year event to a 1 in 100 year event, with a further $50 \mathrm{~cm}$ rise bringing this down to a 1 in 10 year event. ${ }^{6}$

Why is the sea level rising? Because the ocean is getting warmer, and if you warm a liquid it expands. The ocean is on average 4 $\mathrm{km}$ deep, so you don't have to warm it very much to see a significant rise. Remember that the traditional way of measuring temperatures was to put a liquid — either alcohol or mercury—in a glass bulb with a graduated tube. As you warmed it up the liquid would expand. In the case of the Earth, gravity is very conveniently holding the liquid on to the planet, and we can see it expand by looking at these satellite data.

The other place to look for evidence of warming is the cryosphere, where water is frozen. The cryosphere is showing accelerating melting, and some of that water is flowing into the ocean and raising sea level. Parts of the ice sheets of Greenland and of Antarctica are growing because a warmer atmosphere carries more moisture and dumps more snow on the very high, cold plateaux. But around the edges-where the temperature is on average about zero degrees-we see very substantial acceleration in the loss of ice in many places, which is also contributing to the rise in sea level. Of course the ice does not have to melt to raise sea level. Archimedes would have understood that ice that slides off the land into the ocean displaces its own mass of water and raises sea level also. It can then melt at its leisure without further effect.

We also see strong warming in the Arctic basin, which is an ocean covered with a thin crust of floating ice. Satellite data show a very dramatic increase in the amount of melting in the summers of the last 30 years. The area of minimum summer ice cover has been reducing at about $7 \%$ a year. The record in 2007 was almost but not quite broken in 2011, with huge impacts in terms of the connection between the ocean and the atmosphere in the Arctic. This reduction will completely change the dynamics of that coupling, affecting high and mid-latitude weather, and will change the characteristics of the biology in the entire region. The loss of summer ice and opening of ship access will have major geopolitical consequences also.

\section{Is it us?}

We have seen that the planet is warming, but we have also seen that this could be for all sorts of reasons. How can we tell if it is us? If the planet is warming because of the enhanced greenhouse effect we would expect to see more infrared radiation coming back at the surface from the atmosphere. We would expect to see less infrared radiation making its way out into space. Both of these are found to be true from measurements made on the ground and by satellites. Very difficult measurements - lots of noise; very noisy signal—but the evidence is emerging.

We would also expect to see the warming that has occurred over the last 40 or 50 years being stronger by night than by day, and stronger in winter than in summer. And again the data support that. But for me a clinching piece of evidence is that if it were the Sun that had warmed up (we make measurements of the Sun; we know it hasn't) you would expect the whole atmosphere to warm. If it's greenhouse gases that are reducing the amount of heat making its way through the atmosphere to space, you would expect the lower part of the atmosphere to warm, and you would expect the stratosphere to cool. And indeed we see stratospheric cooling. So is it us? The fingerprint, the pattern, says yes.

Of course it's always possible to find some temperature records somewhere that go the other way, or some glacier growth somewhere that implies local cooling. But that's because it's a hugely complex system with lots of processes going on within and lots of local and regional variations. You need to look at the overall pattern to decide and it is this pattern that has led the IPCC to conclude that humans are the dominant cause, ${ }^{4}$ and the science academies of the world to agree. ${ }^{7}$ 


\section{Does it matter?}

The climate system is interconnected. Think of it as a heat engine. More heat comes in at the equator than at the poles. It is the fluids of the planet that transport this heat from the warmer areas to the colder areas, creating the winds that carry and distribute water vapour around the planet in patterns that we have inherited-that civilisation has inherited—and to which we have adapted, for our water supplies, our food supplies, our transport systems, and much more. Changes can be disruptive. Recall that it was the UK government that blamed the snow and unusual cold spell just before Christmas 2010 for a $0.5 \%$ drop in GDP. So economies are brittle to extreme events, underscoring the fact that climate change matters, not just to the poor people of the world, but to all of us.

We are in any case imperfectly adapted to the climate system that we have inherited. The irregular sequence of changing conditions in the Pacific, known as El Niño and La Niña, connects to other regions of the world, including the grain belts in South America and in Africa. During a strong El Niño there can be a loss of up to $50 \%$ of grain harvest in those areas.

Moreover, we know that the climatic zones themselves are able to shift. A stark example is provided by the Sahara, which is now a featureless desert supporting very few people leading a very harsh lifestyle. But about 5000 years ago the Sahara was a verdant zone with a huge east-west river system running across it. The landscape supported vegetation and even hippopotami. We know about this change because satellite radar has imaged through several metres of arid desert sand to reveal the pattern of dried up and choked river channels lying beneath (see fig 2). $\Downarrow$ A massive regional shift in climate had a huge impact on this area, as a result of a massive change in the availability of water.

As Nick Stern noted in his report on the economics of climate change, ${ }^{8}$ the prime interaction between climate change and humans is mediated through water; either extreme lack through extensive drought, or extreme excess through massive inundations and floods. And we are beginning to see the patterns of extreme flooding and extreme drought that are suggestive of climatic change taking place now. There is not a climatologist that would put their hand on their heart and say that the trend is yet statistically significant. But the frequency and patterns of 100 year events that we have been observing over the past few years is beginning to look suspicious. How long should we wait while the statistics grow before we take prudent action?

\section{Conclusion}

A consensus has developed that we should limit the concentration of carbon dioxide in the atmosphere to 450 parts per million in order to avoid the degree of climate change that has been judged to be dangerous to humanity. If we don't do more than we're doing now to reduce our carbon emissions, then the projections for energy demand (a 36\% increase by
2030), ${ }^{9}$ suggest that we could experience not just an atmospheric concentration of 450 parts per million of carbon dioxide by the end of the century, or even 650 parts per million, but that 1000 parts per million or more could be feasible. That would be ten times the change that took place between the last ice age and the current interglacial period, and would force a warming far beyond the $2^{\circ} \mathrm{C}$ deemed safe. You would have to be very optimistic to believe that under those circumstances things would be fine and humanity could simply adapt. A corporate leader who ignored such an evident material risk to the future wellbeing of their business would be deemed reckless, and would be dealt with harshly by stakeholders and history. This is the moment-a turning point in human affairs - for all of us who can influence human carbon emissions to step up to our responsibilities and ensure real and effective action.

$\mathrm{CR}$ has run the International Geosphere-Biosphere Programme, the British Antarctic Survey, and the Science Museum in London. He was one of the architects of the International Polar Year 2008-2009, and President of the Scientific Committee on Antarctic Research. His current interests include the the communication of climate science and the science-policy interface. This article arose from an invitation to speak at a conference on health and security aspects of climate change. CR is guarantor.

Competing interests: The author has completed the ICMJE uniform disclosure form at www.icmje.org/coi_disclosure.pdf (available on request from the corresponding author) and declares: no support from any organisation for the submitted work; no financial relationships with any organisations that might have an interest in the submitted work in the previous three years; no other relationships or activities that could appear to have influenced the submitted work.

Provenance and peer review: Commissioned; not externally peer reviewed.

1 Lovelock JE. Gaia: a new look at life on earth. Oxford University Press, 2000.

2 Crutzen PJ, Stoermer EF. The anthropocene. International Geosphere-Biosphere Programme newsletter 41, 2000.

3 Luthi D, Le Floch M, Bereiter B, Blunier T, Barnola J-M, Siegenthaler U, et al. High-resolution carbon dioxide concentration record 650 000-800 000 years before present. Nature 2008;453:379-82.

4 Solomon S, Qin D, Manning M, Chen Z, Marquis M, Averyt KB, et al. eds. Climate change 2007: the physical science basis. contribution of working group $i$ to the fourth assessment report of the intergovernmental panel on climate change. Cambridge University Press, 2007. www.ipcc.ch/publications_and data/publications_ipcc fourth_assessment_report wg1_report_the_physical_science_basis.htm.

5 Allison I, Bindoff NL, Bindschadler RA, Cox PM, de Noblet N, England MH, et al. The Copenhagen Diagnosis, 2009: updating the world on the latest climate science. The University of New South Wales Climate Change Research Centre (CCRC), 2009.

6 Dawson RJ, Hall JW, Bates PD, Nicholls RJ. Quantified analysis of the probability of flooding in the Thames estuary under imaginable worst-case sea level rise scenarios. Water Resources Development 2005;21:577-59.

7 Showstack R. Science academies' statement on climate change. Eos Trans AGU 2009;90:216.

8 Stern N. Stern review on the economics of climate change. HM Treasury, 2006. www.hmtreasury.gov.uk/stern review report.htm.

9 International Energy Agency. World Energy Outlook 2010. Executive Summary. 2010. www.iea.org/Textbase/npsum/weo2010sum.pdf.

Accepted: 27 January 2012

Cite this as: BMJ 2012;344:e1026

(c) BMJ Publishing Group Ltd 2012 


\section{Figures}

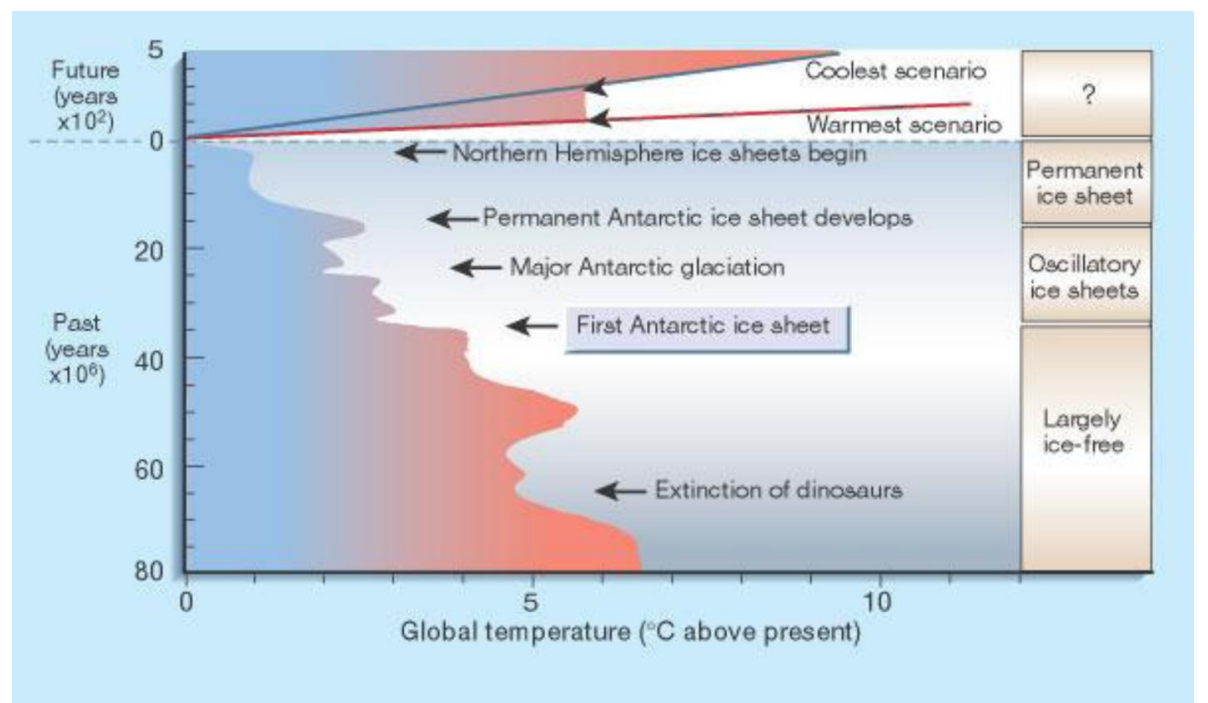

Fig 1 Significant transitions in Antarctic glacial history including the sharp cooling associated with the formation of the first Antarctic ice sheet, 34 million years ago, ascribed to a decrease in the concentration of atmospheric $\mathrm{CO}_{2}$. Global temperature projections for the future from the Intergovernmental Panel on Climate Change (IPCC) are shown on a greatly expanded timescale. Barrett P. Palaeoclimatology: cooling a continent. Nature 2003;421:221-3

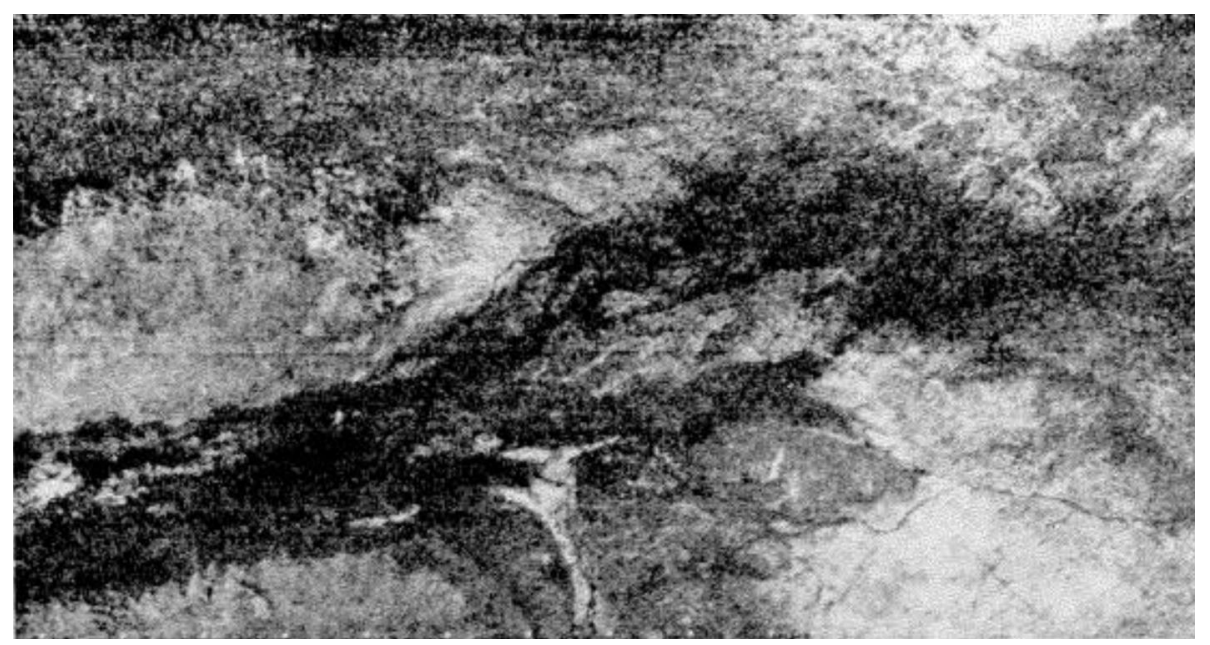

Fig 2 A dried up river bed in the Sahara imaged through the desert sand by the spaceborne Shuttle Imaging Radar (SIR-A). Elachi C. Seeing under the Sahara: spaceborne imaging radar. Engineering and Science September 1983; 4-8 